\title{
LOGÍSTICA REVERSA DE BATERIAS AUTOMOTIVAS
}

\author{
Ayrla Maria De Jesus (UPE - Campus Salgueiro) ayrlamaria22@ @otmail.com \\ Tiago Silveira Machado (UPE - Campus Salgueiro) tiago.machado@upe.br \\ Wanderberg Alves Brandão (UPE - Campus Salgueiro) wanderberg.brandao@upe.br
}

\begin{abstract}
Resumo
Buscando proporcionar uma melhoria na cadeia de suprimentos, a logística reversa proporciona condições para proporcionar a reversibilidade de componentes que estão no final do uso. O objetivo desta pesquisa foi de descrever por meio da revisão bibliográfica um estudo relacionado ao processo de logística reversa de baterias automotivas pós-consumo. Metodologicamente, buscou-se desenvolver uma pesquisa bibliográfica, aplicada, de caráter qualitativo. Os resultados revelam que ainda existe um longo caminho com relação a logística reversa, uma vez que ainda não foi definido um modelo que seja facilmente aplicado nas empresas brasileiras, o que abre novas possibilidades de pesquisa neste contexto. Além disso, os resultados sugerem que a formação dos gestores deve exceder o que a legislação contempla de modo que seja possível desenvolver modelos de gestão que abordem aspectos relacionados a gestão dos recursos disponíveis.
\end{abstract}

Palavras-Chaves: Logística Reversa. Baterias Automotivas. Meio Ambiente.

\section{Introdução}

Nos últimos anos, as empresas tem buscado participar de arranjos organizacionais com o propósito de desenvolver mecanismos para diminuir riscos e por consequência compartilhar os seus ganhos. Christopher (1997) percebeu essa mudança de comportamento organizacional devido a concorrência individual ser mais acirrada do que em contexto de competição entre as cadeias logísticas nas quais as empresas estão inseridas.

Numa época em que a diferenciação de produtos e serviços demandados se torna cada vez mais presente e necessária, a qualidade do gerenciamento e do desempenho da cadeia logística se apresenta como uma poderosa fonte de vantagem competitiva (CHRISTOPHER, 1997), todos os processos logísticos passaram a ser mapeados e controlados de modo que fosse possível identificar quais agentes poderiam atuar e contribuir para aperfeiçoamento do seu core business, tendo em vista que a empresa se dedicará em desempenhar o papel relacionado ao seu negócio principal.

Com isso, a gestão da cadeia logística, apesar de apresentar-se como complexa no contexto global, para os seus participantes pode ser vista de forma simplificada, uma vez que a gestão das operações de transporte e armazenagem, bem como o gerenciamento de informações 
correlatas a estas operações, tornam-se uma atividade limitada a sua proposta de negócios, mas que no contexto da cadeia se torna de extrema importância (CHRISTOPHER, 1997).

Dentre as diversas cadeias existentes no mercado, o setor automotivo apresenta uma estrutura bastante robusta no que diz respeito ao número de participantes, como na quantidade de montadoras que fazem parte desta estrutura. Devido à sua complexidade, o setor automotivo necessita de imperativa integração dos fornecedores na sua cadeia de suprimentos, tornandose imprescindível a disponibilidade de um sistema de planejamento e controle da produção eficaz, que permita à empresa gerenciar a demanda, os materiais, a capacidade produtiva e a produção (MESQUITA; CASTRO, 2008).

Atualmente um dos assuntos que vem se destacando no setor industrial é a logística reversa, que visa reduzir os impactos ambientais e atuar diretamente no ciclo de vida do produto desde a matéria-prima até seu consumo final, retornando à indústria fabricante para que a mesma possa dá-lo um destino ecologicamente correto (MUELLER, 2005). E como a estrutura dos veículos apresentam diversos componentes que são recicláveis, estudos nesta área contribuem para o aperfeiçoamento desta cadeia, uma vez que todos os elos desta estrutura estão interligados.

Segundo Silva (2018), seu estudo identificou alguns fatores existentes para que a logística reversa seja aplicada. Estes fatores contribuem para precisam desenvolver meios para potencializarem seus recursos e assim, proporcionar maior competitividade a cadeia.

a) Econômicos: tem referência como custo da produção, pois, precisam de adaptação dos produtos e processos para evitar ou diminuir o impacto ao meio ambiente;

b) Governamentais: ligada à legislação e à política do meio ambiente;

c) Responsabilidade corporativa: associada ao envolvimento das empresas fabricantes com a coleta de seus produtos ao final da vida útil;

d) Tecnológicos: ligada aos avanços tecnológicos da reciclagem e projetos de produtos que tem por finalidade a reutilização dos produtos após descarte pela sociedade;

e) Logísticos: relacionado aos aspectos logísticos da cadeia reversa, como a coleta de produtos.

A logística reversa tem por finalidade gerenciar de forma contrária a logística tradicional, considerando o fluxo dos produtos do seu ponto de consumo até à sua origem para 
reincorporação ao ciclo de negócios através de reciclagem, remanufatura, envio para mercados secundários, destinação final, entre outras maneiras (SOUSA; RODRIGUES, 2014).

A logística reversa proporciona o retorno do material pelo consumidor não apenas para o fornecedor direto, mas também para seu fabricante. $O$ fabricante, por sua vez, se responsabiliza pela reciclagem ou reutilização do produto como insumo. Dada a destinação correta ao material, o mesmo poderá ser devolvido novamente ao mercado consumidor quando viável (BELGAMASCO; SILVA; ANGELIS NETO, 2017; VIEIRA et al., 2009).

\footnotetext{
É a responsabilidade socioambiental que direciona todos os canais, juntamente com a legislação e a economia, que se encaixam muito bem na prática desse sistema, ou seja, a legislação impõe que baterias automotivas compradas seja igual ao número de sucatas repassadas, fazendo com que seja obrigatório o sistema de Logística Reversa, e a economia, pois a comercialização dessas baterias inservíveis gera lucro e redução de custos na hora da compra, já que os fabricantes oferecem desconto (BELGAMASCO; SILVA; ANGELIS NETO, 2017, p. 24).
}

Esta responsabilidade quando devidamente desenvolvida, pode trazer benefícios para a cadeia de suprimentos, entretanto, se houverem gaps nos seus processos, fatores complicadores podem prejudicar na destinação correta dos componentes que estão no fluxo reverso. Neste contexto, o objetivo desta pesquisa é descrever a importância do processo de logística reversa de baterias automotivas identificado na literatura.

Inicialmente, esta pesquisa justifica-se pelo fato de que as baterias automotivas são compostas por uma grande quantidade de componentes que são poluidores, os quais, após sua vida útil, precisam ser destinados adequadamente. Além disso, nos últimos anos, com o esgotamento de jazidas de chumbo (matéria-prima fundamental na fabricação de baterias) localizadas no estado e Minas Gerais, hoje a obtenção brasileira se aplica primordialmente no mercado secundário através da reciclagem, ou por meio de importação de diversos outros países (BELGAMASCO; SILVA; ANGELIS NETO, 2017).

Além disso, Sousa e Rodrigues (2014) afirmam que o descarte inadequado de baterias pode ocasionar a contaminação do solo, pois possuem substâncias corrosivas e tóxicas devido ao chumbo-ácido fazer parte da sua constituição. Já para a saúde humana, devido seu nível de toxicidade, o chumbo das baterias proporciona doenças e sérios riscos de vida.

Academicamente, este trabalho traz como contribuição as relações de aprendizado por meio da aplicação de um conhecimento teórico com a prática, uma vez que é possível identificar in 
loco como acontece a Logística Reversa das baterias na cidade de Salgueiro, podendo identificar por meio desta pesquisa se a legislação está sendo seguida e se os critérios estabelecidos em lei estão sendo respeitados. Com isso, será possível apresentar um mapeamento dos processos, de modo que seja capaz de identificar pontos de melhoria do processo e desenvolver comparativos com relação aos modelos desenvolvidos em outras localidades.

Estas contribuições se estendem a uma perspectiva social uma que a pesquisadora abrange a sua formação neste segmento específico, uma vez que este é um ponto de interesse no que se diz respeito ao seu conhecimento, além da possibilidade de garantir que a sociedade local estará ciente da sua realidade com relação ao desenvolvimento sustentável na perspectiva socio-econômico-ambiental.

\section{Metodologia}

Metodologicamente, buscou-se desenvolver uma pesquisa bibliográfica, aplicada, de caráter qualitativo, buscando caracterizar a compreensão detalhada do contexto investigado por meio da perspectiva dos entrevistados (GIL, 2002). Para isso, bases de dados do Google Acadêmico foram consultadas, além da SciELO, para desenvolvimento das considerações teóricas.

De posse das informações levantadas, foi desenvolvido um estudo teórico relacionando as informações levantadas com os objetivos desta pesquisa. Assim, foi elaborado o arcabouço teórico geral diante do panorama estudado.

\section{Cadeia de Suprimentos Automotiva}

Analisando a competitividade das empresas nos últimos anos, percebe-se que o acirramento dos últimos anos tem levado as organizações a buscarem alternativas de redução de custo, aumento de eficiência e desenvolvimento de relacionamentos com os seus parceiros para aumento de competitividade. Para isso, as empresas tem adotado parcerias com a Cadeia de Suprimentos como alternativa para esse desenvolvimento.

A gestão dentro da cadeia de suprimentos precisa compreender as etapas de planejamento e controle das operações incluídas nas atividades de suprimento e compras, armazenagem, transformação e todas as atividades logísticas de distribuição física dos produtos (MESQUITA; CASTRO, 2008). Por meio desse controle, a competição real não é feita entre 
uma companhia e outra, mas entre a cadeia logística na qual a empresa está inserida e a dos seus concorrentes (CHRISTOPHER, 1997, p. 15).

Logo, quanto mais eficiente for uma cadeia de suprimentos, mais competitivo serão os seus membros. Para Christopher (1997, p. 13), “a cadeia de suprimentos representa uma rede de organizações, através de ligações, nos dois sentidos, dos diferentes processos e atividades que produzem valor na forma de produtos e serviços que são colocados nas mãos do consumidor final". Essa competitividade se estende a todos os segmentos e o setor automotivo apresenta grande representatividade pela sua participação e contribuição comercial.

A pesquisa de Santos (2017) revela que a indústria automobilística tem um peso significativo sobre a economia mundial, pois suas unidades fabris estão espalhadas na maioria dos continentes, o que proporciona o emprego de milhares de pessoas, apresenta contribuições expressivas aos PIB's destas nações onde seus parques industriais estão instalados. Com isso, no aquecimento de mercado, a indústria automotiva por meio de suas montadoras "puxam" os outros elos da cadeia por meio do sistema de produção enxuto (MESQUITA; CASTRO, 2008).

Apesar da análise do sistema de produção não ser o foco desta pesquisa, é necessário salientar a sua importância pela necessidade de colaboração que a Cadeia de Suprimentos, que segundo Carvalho (2008) é o processo de integração organizacional que tem levou ao desenvolvimento de um modelo de produção que traz os seus fornecedores para próximos, de modo que essa parceria proporcione grande produtividade na indústria automobilística, além da consciência de colaboração de seus parceiros.

O cenário mundial revela que houve uma ascensão no número de carros vendidos, segundo a Organização Internacional dos Fabricantes de Automóveis (OICA), em 2019 foi ultrapassada a marca de 1,2 bilhão de carros no mundo. O relatório revela que o mercado nacional só está atrás de países como Estados Unidos, China e Japão. Dados da Focus2Move (2019) revelam que mesmo com as vendas globais de carros apresentando crescimento de $0,2 \%$, o mercado prepara-se para um crescimento robusto, fortalecendo suas projeções para o cenário futuro.

Quando analisaram o histórico nacional de pesquisas sobre o tema, Mesquita e Castro (2008) perceberam que a cadeia automotiva brasileira tem sido objeto de várias pesquisas em gestão de operações devido ao seu rápido crescimento e à sua grande importância para a economia 
do país. Isso se deve pelos incentivos governamentais, ascensão econômica populacional e maior oferta de crédito, que segundo o Sindipeças (2016), em 2015, a frota alcançou um montante de 42,6 milhões de veículos, incluídos automóveis, comerciais leves, caminhões e ônibus, número $2,5 \%$ superior ao de 2014.

Segundo a ANFAVEA (2016), ocorreu um desaquecimento na produção durante o ano de 2015, entretanto, essa cadeia tem sido bastante representativa desde a década de 1990, quando o mercado nacional foi aberto e novas montadoras passaram a competir por parcelas do mercado. Entretanto, no cenário recente, Santos (2017) revela que além da recessão em que o país se encontra atualmente, outro fator que afetou a produção de veículos foi o fim do período de isenção dos impostos sobre produtos industrializados (IPI), o que afetou todos os seguimentos da indústria de transformação, entretanto, no segmento automobilístico a queda na demanda foi mais elevada. Desse modo, as montadoras precisaram repensar seus modelos de produção com o propósito de torna-los mais eficientes.

\footnotetext{
As montadoras modernizaram as unidades industriais e expandiram a produção em resposta ao crescimento do mercado consumidor. Por outro lado, o setor de autopeças passou por uma profunda crise estrutural, com fechamento de fábricas e aumento da importação de produtos acabados. Com a retomada do crescimento da produção, aumentou a pressão por fornecimento com prazos curtos, maior qualidade e menores custos. Esta pressão estende-se também para os fornecedores de segunda e terceira camadas da cadeia de suprimentos, que atendem um número maior de clientes e com maior variedade de produtos (MESQUITA; CASTRO, 2008, p. 33).
}

Com isso, a Responsabilidade Compartilhada tornou-se fundamental junto ao ciclo de vida dos produtos, pois por meio dele, as organizações compartilham tecnologias, ganhos, experiências e responsabilidades, tendo em vista que após o seu uso, um grande passivo do setor automobilístico tem isso o manejo dos resíduos sólidos.

Parte desses resíduos é reaproveitada, mas alguns componentes dos automóveis precisam de maior atenção, tendo em vista que a responsabilidade envolve todas as partes envolvidas, sejam consumidores, empresários, fabricantes ou comerciantes. a gestão não correta destes produtos usados pode nos gerar, inúmeros problemas e danos ao nosso meio ambiente, além de comprometer a qualidade de vida dos seres em nosso planeta e até do mesmo.

Com isso, a vertente da Logística Reversa emerge como alternativa para aproveitamento dos recursos, além da destinação adequada dos componentes que não são reaproveitados. Essa nova abordagem de implementação dos sistemas para a reutilização e reciclagem de resíduos e rejeitos automotivos pode contribuir diretamente para o aumento da competitividade, uma 
vez que os recursos que estão se tornando cada vez mais escassos sejam aproveitados e os que não são utilizados sejam devidamente destinados.

\section{Logística reversa no setor automotivo}

A Logística consiste no gerenciamento do fluxo de materiais desde seu ponto de aquisição até o seu ponto de consumo, ou seja, vai desde sua matéria prima até o consumidor final, trazendo o retorno desses materiais ao ciclo inicial através do descarte adequado ou reciclagem (SILVA, 2018). é importante identificar os níveis de serviços demandados nos mercados onde a empresa atua e, a partir desta realidade, desenvolver soluções logísticas de baixo custo (CHRISTOPHER, 1997).

O conceito de logística reversa é bastante amplo, por isso, não devemos entendê-la como apenas um recolhimento de produtos defeituosos, ou coisa do gênero, pois o processo está ligado a todas as operações relacionadas com a reutilização de produtos e materiais, englobando todas as atividades de logísticas de coletar, desmontar, e processar produtos ou materiais, a fim de assegurar uma recuperação sustentável (LEITE, 2003).

De acordo com o estudo de Sousa e Rodrigues (2014), este tema é recente na literatura, a partir da década de 80 as empresas começaram a se preocupar com o fluxo contrário nas cadeias produtivas, visando reduzir os impactos ambientais causados por resíduos (PEREIRA et al. 2012; CHAVES E BATALHA 2006; apud MILANO E LIZARELLI, 2013).

Belgamasco, Silva e Angelis Neto (2017) identificaram que os estudos primários sobre logística reversa são identificados nas décadas de 1970 e 1980. O objetivo dessas pesquisas estava voltado principalmente para o retorno de materiais para reciclagem.

Com isso, foram desenvolvidos estudos vinculados às universidades na década de 1990, buscando observar a área sob uma visão acadêmica e científica. Neste cenário foi estudado a diminuição de ciclo de vida dos produtos, o reconhecimento de novas possibilidades competitivas pela minimização de custos, a procura pela geração de imagens corporativas ligadas à responsabilidade socioambiental, o crescimento de legislações coercitivas sobre o tema (ABREU et al., 2010).

O detalhamento deste cenário proporcionou a possiblidade de identificar o ponto de partida do estudo no campo da Logística Reversa, o que possibilita o desenvolvimento de estudos 
ligados aos desdobramentos destas pesquisas. Nesse sentido, o reaproveitamento de materiais apresenta-se como um campo de pesquisa bastante fértil.

Silva (2018) mostra que muitas vezes o produto descartado, no todo ou em partes, já não tem serventia alguma ao processo industrial. Nesse caso, há necessidade de se garantir a disposição final dos mesmos de forma segura para a população e para o meio ambiente.

A logística reversa está ligada, ao mesmo tempo, às questões legais e ambientais e as econômicas, o que se coloca em destaque e faz com que seja necessário compreender como as empresas lidam com os seus rejeitos, e a logística reversa, relaciona todas as atividades logísticas de coleta, desmonte, processamento de produtos, com o intuito de assegurar uma recuperação sustentável do ponto de vista ambiental (REVLOG, 2009).

No contexto automobilístico, Pinto (2012) afirma que em média $66 \%$ dos carros são compostos por aço, $9 \%$ de plástico, $6 \%$ de alumínio, $4 \%$ de borracha, $3 \%$ de vidros e $2 \%$ de zinco, cobre e chumbo. Mesmo com um percentual tão baixo, componentes a base de chumbo podem trazer alguns riscos a saúde e ao meio ambiente, o que exige uma necessidade no cuidado desses rejeitos.

Com isso, houve um aumento na sensibilidade ecológica das pessoas, para implantação da logística reversa de pós-consumo nas empresas. As pessoas estão mais cientes sobre as responsabilidades ambientais que as empresas devem ter para que não prejudiquem ao meio ambiente (SOUSA; RODRIGUES, 2014).

Segundo Silva (2018) os canais de distribuição reverso cuidam do fluxo contrário ao tradicional de produtos e de materiais, pois tratam do acompanhamento até o descarte de componentes após sua utilidade, que podem fazer encaminhamentos para aproveitamento em outros ciclos produtivos de alguma forma. Neste contexto, a próxima seção aborda uma breve revisão do estudo de baterias automotivas, no contexto da sustentabilidade e do reaproveitamento dos seus componentes.

\section{Baterias automotivas no contexto sustentável}

No contexto atual, as práticas de responsabilidade ambiental são fundamentais para a sobrevivência das organizações na atualidade. Elas têm se destacado em muitas empresas nos últimos anos, através do desenvolvimento e ampliação de projetos sociais, através de 
parcerias com governos e instituições do terceiro setor na busca de novas propostas ao cenário apresentado (BELGAMASCO; SILVA; ANGELIS NETO, 2017).

Esta perspectiva está alinhada com a perspectiva de Christopher (1997) pois defende que as organizações devem desenvolver cadeias logísticas ágeis e o desenvolvimento da agilidade como uma vantagem competitiva requer estruturas organizacionais flexíveis, processos logísticos adequados e sistemas de informações eficientes. Já na logística reversa, existem meios para recuperar produtos já utilizados, agregando valor em diversos setores como o econômico, ambiental e logístico através da reutilização, reciclagem e incineração desses materiais, fazendo com que os mesmos sejam reintegrados ao ciclo produtivo (SILVA, 2018).

Uma bateria automotiva tem a finalidade de dar partida elétrica ao motor de partida e ao sistema de ignição de um veículo além de auxiliar o alternador e estabilizar o sistema elétrico do veículo (SANTOS et al. 2012). Este componente é fundamental, uma vez que a parte elétrica depende fundamentalmente da bateria para início do mecanismo e manutenção da carga.

Segundo a Associação Brasileira da Indústria Elétrica e Eletrônica (ABINEE, 2013), atualmente, no Brasil, são produzidas 800 milhões de pilhas e 17 milhões de baterias por ano, sendo $80 \%$ de pilhas secas (zinco e carbono) e $20 \%$ de pilhas alcalinas, e não há estimativas de baterias e pilhas que são recolhidas e recicladas ou descartadas de forma correta. As vendas de baterias automotivas brasileira têm crescido consideravelmente devido ao crescimento da frota circulante de veículos nos últimos anos (FERNANDES et al., 2010).

As baterias automotivas compostas por chumbo possuem toxicidade que quando descartadas de forma inadequada podem causar graves danos ambientais e a saúde de pessoas que trabalham diretamente com estes objetos sem a devida proteção (SOUSA; RODRIGUES, 2014).

Segundo a resolução $n^{\circ} 401$ do CONAMA (2008) as baterias que contenham em suas composições chumbo, cádmio, mercúrios e seus compostos, deverão ser entregues pelos usuários aos estabelecimentos que as comercializem ou a rede de assistência técnica autorizada, para repasse aos fabricantes ou importadores, para que estes adotem, diretamente ou por meio de terceiros, os procedimentos de reutilização, reciclagem, tratamento ou disposição final ambientalmente adequada. 
Os processos de abertura e quebra de baterias devem ser realizados com dispositivos mecanizados e em locais específicos. As fontes mais comuns de contaminação ambiental seriam: poeiras contaminadas com chumbo e eletrólito ácido, chumbo particulado e detritos contaminados (SOUSA; RODRIGUES, 2014; JOST, 2001; PAOLIELLO; CHASIN, 2001).

\section{Resultados}

Os resultados revelam que Para a realização da logística reversa de baterias automotivas, as etapas de coleta, separação e acondicionamento, movimentação e transporte, só podem ser desenvolvidas e consolidadas por meio da responsabilidade socioambiental (BELGAMASCO; SILVA; ANGELIS NETO, 2017).

Além disso, a necessidade de mapear a cadeia produtiva reversa, pode contribuir para o desenvolvimento de mecanismos de controle relacionados aos elementos que podem impactar ambientalmente os elos da produção, como os envolvidos no processo.

Os achados revelam que a tendência organizacional é que as empresas tendem a desenvolver modelos de gestão que contemplem aspectos ambientais, além do fato de que as empresas que lideram o mercado neste aspecto, como acontece no setor automotivo, sem apresentado um diferencial competitivo.

\section{Conclusão}

A pesquisa contribuiu na compreensão da importância da logística reversa no que se diz respeito a logística reversa de baterias automotivas. Para isso foi feito um estudo de toda a cadeia produtiva, além da necessidade de compreender o desenvolvimento dos elementos logísticos buscando soluções para minimização de danos causados ao ambiente, bem como para agregar valor às atividades operacionais de uma empresa que as comercializam.

Sugere-se o desenvolvimento de novas pesquisas que busquem desenvolver estudos relacionados a modelos de avaliação do ciclo de vida de produtos, além de testar estes modelos qualitativa e quantitativamente.

Por fim, a pesquisa abre novas possibilidades para que a formação de profissionais que trabalham na área de gestão contemple estes aspectos, não se limitando apenas a cumprir a legislação vigente, mas contemplando aspectos relacionados a gestão dos recursos disponíveis. 


\section{Referências}

BELGAMASCO, Maria Eduarda Fagan; SILVA, Tamyris Tavares da; ANGELIS NETO, Generoso de. Logística reversa de baterias automotivas: um estudo de caso em uma distribuidora de autopeças. 2017.

BORELLA, M.R.C.; BORELLA, I.L. Mudanças na logística de processos e na logística de informação: estudo de caso longitudinal de uma empresa membro de cadeia de suprimento. In: ENCONTRO NACIONAL DE ENGENHARIA DE PRODUÇÃO, 32, 2

CARVALHO, Enéas Gonçalves. Inovação tecnológica na indústria automobilística: características e evolução recente. Economia e Sociedade, Campinas, v. 17, n. 3 (34), p. 429-461, dez. 2008.

CASTRO, Ana; DOS SANTOS, VANIA SOUZA. Gestão da Cadeia de Suprimentos.2017

CHRISTOPHER, Martin. Logística e Gerenciamento da Cadeia de Suprimentos: estratégias para a redução de custos e melhoria dos serviços. São Paulo: Pioneira Thomson Learning, 1997.

FERNANDES, J. D.; DANTAS, E. R. B.; BARBOSA, J. N.; BARBOSA, E. A. Estudo de impactos ambientais em solos: o caso da reciclagem de baterias automotivas usadas, tipo chumbo-ácido. Revista Brasileira de Gestão e Desenvolvimento Regional, Taubaté - SP, v. 7, nº. 1, p. 231-255.

MESQUITA, M. A. de; CASTRO, R. L. de. Análise das práticas de planejamento e controle da produção em fornecedores da cadeia automotiva brasileira. Gestão e Produção, v. 15, n. 1, p. 33-42, 2008.

MOTTA, Giseli Paula et al. Logística reversa em baterias automotivas: um estudo na Pioneiro Ecometais Ltda. 2009.

REVLOG. EUROPEAN WORKING GROUP ON REVERSE LOGISTICA ACOSTA, B.; PADULA, A. D.; PÉREZ, P.; A Logística Reversa na indústria de Produtos Informáticos: explorando os mecanismos utilizados pelas empresas no tratamento do lixoinformático. In: XXXIV Encontro Nacional de Pós-graduação e Pesquisa em Administração - ENANPAD. Anais... Rio de Janeiro-RJ, 25 a 29 de setembro de 2010.

SANTOS, A. C. de Q.; MORAIS, S. F. A.; ARAUJO, M. C. B. de; MARTINS, D. R.; SCHRAMM, F. Aplicação do Masp para a melhoria da eficiência do processo produtivo em uma indústria de baterias automotivas. In: XXXII ENCONTRO NACIONAL DE ENGENHARIA DE PRODUÇÃO-ENEGEP. Anais... Bento Gonçalves- RS, 15 a 18 de outubro de 2012.

SILVA, Letícia Müller. A importância da logística reversa no pós-consumo. 2018. 25 folhas. Trabalho de Conclusão de Curso (Graduação em Administração) - Anhanguera, Pelotas, 2018.

SOUSA, J. V. de O.; RODRIGUES, STÊNIO LIMA. Logística reversa de baterias automotivas: estudo de caso em uma rede autocentros do Estado do Piauí. Anais Encontro Internacional sobre Gestão Empresarial e Meio Ambiente, v. 16, 2014.

SOUSA, J. V. O; RODRIGUES, S. L. Logística Reversa de baterias automotivas: estudo de caso em uma rede autocentros do Estado do Piauí. ENGEMA - Encontro Internacional sobre Gestão de Empresarial e Meio Ambiente. ISSN 2349-1048. 2014. Disponível em:<http://www.engema.org.br/XVIENGEMA/24.pdf>. Acesso em: 25 de julho de 2016. 